\title{
The reliability of the Greulich and Pyle atlas when applied to a Southern Turkish population
}

\author{
Ozge Erken Gungor ${ }^{1}$, Mevlut Celikoglu², Burak Kale ${ }^{2}$, Ahmet Yalcin Gungor ${ }^{2}$, Zafer Sari
}

Correspondence: Dr. Mevlut Celikoglu

Email: mevlutcelikoglu@hotmail.com
'Department of Pediatric Dentistry, Faculty of Dentistry, University of Akdeniz, Antalya, Turkiye,

${ }^{2}$ Department of Orthodontics, Faculty of Dentistry,

University of Akdeniz, Antalya, Turkiye

\begin{abstract}
Objective: The aim of this study was to evaluate the applicability of Greulich and Pyle(GP) method for Southern Turkish population. Materials and Methods: Hand and wrist radiographs of 535 patients (276 females, 259 males aged from 10 to 18 years) selected retrospectively from the archive. Skeletal age (SA) estimation was performed according to GP atlas. The chronological age (CA) and SA were compared using the Paired $t$-test. Results: The mean difference between the CA and SA ranged from 0.07 to 1.11 years. These differences between the CA and estimated SA were statistically significant in group I $(10-10.90$ years $)(P<0.001)$, group II (11-11.90 years) $(P<0.050)$, group III $(12-12.90$ years $)(P<0.001)$, group IV $(13-13.90$ years $)(P<0.010)$, and group V $(14-14.90$ years $)(P<0.001)$ for females. The mean difference between the CA and SA ranged from -0.41 to -1.79 years for females. These differences between the CA and estimated SA were statistically significant in all age groups. Conclusions: Statistically significant differences were found in the CA and SA assessed by GP method for the Southern Turkish sample. SA was significantly over-predicted in the 10-15 year ages in males and for 10-18 year ages for females. It is appropriate to use GP method in Southern Turkish children; however, a revision is needed for better results and to minimize the mistakes.
\end{abstract}

Key words: Chronologic age, Greulich and Pyle atlas, skeletal age

\section{INTRODUCTION}

Skeletal age (SA) is an excellent indicator for determination of the growth status, health monitoring, and many diseases including, metabolic and genetic disorders, endocrinology diseases, nutritional disorders, and limb length discrepancies in children. ${ }^{[1,2]}$ SA is usually determined by comparing the left-hand radiograph of children with a standard reference sample as an atlas. ${ }^{[3]}$

Greulich and Pyle (GP) is one of the most famous methods for SA estimation in children. The GP atlas was first introduced in the 1950s and involved the 1000 hand skeletal radiographs of the Caucasian population from of people living in Cleveland, aged between 0 and 18 years. ${ }^{[3]}$ Numerous studies have tested the applicability of this method in various population, including Italian ${ }^{[4]}$ Malay, ${ }^{[3]}$ Indian, ${ }^{[2]}$ Scottish, ${ }^{[5]}$ and they concluded that applicability of the method varies with a population used which means the same method could produce a different result.

Although Cantekin et al. ${ }^{[6]}$ and Koc et al. ${ }^{[7]}$ have tested the applicability of this method in Eastern and Northeastern Turkish population, respectively, to our knowledge, there is no study in the literature that evaluates its applicability of GP method for Southern Turkish population. Thus, the aim of this study was to evaluate the applicability of GP method for Southern Turkish population.

\section{MATERIALS AND METHODS}

Hand and wrist radiographs of 535 patients (276 females, 259 males aged from 10 to 18 years)

\footnotetext{
How to cite this article: Gungor OE, Celikoglu M, Kale B, Gungor AY, Sari Z. The reliability of the Greulich and Pyle atlas when applied to a Southern Turkish population. Eur J Dent 2015;9:251-4.

Copyright () 2015 Dental Investigations Society.

DOI: $10.4103 / 1305-7456.156846$
} 
selected retrospectively from the archives of akdeniz University, Faculty of Dentistry, and Department of Orthodontics. Selection criteria included having good quality of hand and wrist radiographs, born and raised in Southern region of Turkey, no history of chronic or severe physical or mental illnesses, right-handed with no history of trauma or injury to the left hand and wrist. Subjects with skeletal malocclusions including crossbite and sagittal malocclusions, systemic diseases affecting the growth and development of the teeth and tooth agenesis excluding third molars were excluded. Table 1 shows the distribution of the subjects by gender and age. The patients were not exposed to any additional radiation. Therefore, approval from the ethics committee was not required for this retrospective archive study. In addition, as a usual protocol, all the patients (or parents) signed an informed consent agreeing to the use of the patients' data for scientific studies.

Skeletal age estimation was performed according to GP atlas. To ensure contrast enhancement of the hand and wrist images, all assessments were performed by one investigator in a darkened room with a radiographic illuminator with the chronological age (CA) blinded. Radiographs were compared with the GP atlas and the closest image selected for the prediction of bone age. CA was first recorded on a data collection sheet and the SA scores were tabulated later on a separate sheet in order to avoid the examiner bias at the time of collecting data.

\section{Statistical method}

Descriptive statistics was calculated for all measurements. Kolmogorov-Smirnov test was performed to test the normality of the data. Since the results of the Kolmogorov-Smirnov test showed normal distribution, parametric tests were performed. The CA and estimated SA were compared using the Paired $t$-test.

\begin{tabular}{|c|c|c|c|}
\hline Group & Female & Male & Total \\
\hline G1 (10-10.9 years) & 21 & 24 & 45 \\
\hline G2 (11-11.9 years) & 46 & 24 & 70 \\
\hline G3 (12-12.9 years) & 55 & 50 & 105 \\
\hline G4 (13-13.9 years) & 63 & 63 & 126 \\
\hline G5 (14-14.9 years) & 29 & 36 & 65 \\
\hline G6 (15-15.9 years) & 20 & 26 & 46 \\
\hline G7 (16-16.9 years) & 22 & 21 & 43 \\
\hline G8 (17-17.9 years) & 20 & 15 & 35 \\
\hline Total & 276 & 259 & 535 \\
\hline
\end{tabular}

Fifty out of 535 radiographs were randomly selected and re-examined 4 weeks after the initial examination by the same investigator (B.A.) to determine the measurement error. Examination of results using the Paired $t$-test and Houston tests showed no statistically significant differences between the two examinations $(P>0.05)$ and high-reliability scores $(r<0.92)$. All statistical analyses were conducted using SPSS version 17.0.0 (SPSS Inc., Chicago, Ill, USA). Significance for all statistical tests was predetermined at $P<0.05$.

\section{RESULTS}

Table 2 shows the differences between the mean CA and estimated SA using the GP method for different age groups and total sample for males. The mean difference between the CA and estimated SA ranged from 0.07 to 1.11 years. These differences between CA and estimated SA were statistically significant in group I $(10-10.90$ years $)(P<0.001)$, group II (11-11.90 years) $(P<0.050)$, group III (12-12.90 years) ( $P<0.001)$, group IV (13-13.90 years) $(P<0.010)$, and group V $(14-14.90$ years $)(P<0.001)$.

The differences between the mean CA and estimated SA using the GP method for different age groups and total sample for females are shown in Table 3. The mean difference between the CA and SA ranged from -0.41 to -1.79 years. These differences between the CA and estimated SA were statistically significant in all age groups (group I [10-10.90 years] $[P<0.050]$, group II [11-11.90 years] $[P<0.001]$, group III [1212.90 years] $[P<0.010]$, group IV [13-13.90 years] $[P<0.001]$, group V [14-14.90 years] $[P<0.001]$ group VI [15-15.90 years] $[P<0.001]$, group VII [16-16.90 years] $[P<0.010]$, and group VIII [1717.90 years $][P<0.050])$.

\section{DISCUSSION}

Physicians are frequently requested to assess the age of an individual in civil and criminal cases. ${ }^{[1]}$ The study of the epiphyseal union of hand and wrist bones is considered a reasonable scientific and accepted method for estimation of age by courts of law all over the world. ${ }^{[8]}$ GP method is the most popular method in estimating SA, which determination is usually performed by comparing the plain left-hand radiograph of a patient with findings in a normal reference population. ${ }^{[1]}$

In this study, subjects with skeletal malocclusions including crossbite and sagittal malocclusions, systemic 


\begin{tabular}{|c|c|c|c|c|}
\hline Group & $\begin{array}{c}\text { Mean CA } \\
\text { years }\end{array}$ & $\begin{array}{c}\text { Mean SA } \\
\text { years }\end{array}$ & $\begin{array}{c}\text { Mean } \\
\text { difference }\end{array}$ & $P$ \\
\hline \multicolumn{5}{|l|}{ Male } \\
\hline G1 (10-10.9) & $10.35 \pm 0.31$ & $9.35 \pm 1.08$ & 0.99 & 0.000 \\
\hline G2 (11-11.9) & $11.44 \pm 0.35$ & $10.73 \pm 1.44$ & 0.71 & 0.016 \\
\hline G3 (12-12.9) & $12.45 \pm 0.31$ & $11.34 \pm 1.54$ & 1.11 & 0.000 \\
\hline G4 (13-13.9) & $13.32 \pm 0.29$ & $12.68 \pm 1.50$ & 0.64 & 0.001 \\
\hline G5 (14-14.9) & $14.32 \pm 0.30$ & $13.37 \pm 1.47$ & 0.95 & 0.000 \\
\hline G6 (15-15.9) & $15.26 \pm 0.28$ & $14.90 \pm 1.56$ & 0.35 & 0.208 \\
\hline G7 (16-16.9) & $16.18 \pm 0.21$ & $16.11 \pm 1.54$ & 0.07 & 0.827 \\
\hline G8 (17-17.9) & $17.18 \pm 0.21$ & $16.81 \pm 1.05$ & 0.37 & 0.169 \\
\hline
\end{tabular}

\begin{tabular}{|c|c|c|c|c|}
\hline Group & $\begin{array}{c}\text { Mean CA } \\
\text { years }\end{array}$ & $\begin{array}{c}\text { Mean SA } \\
\text { years }\end{array}$ & $\begin{array}{c}\text { Mean } \\
\text { difference }\end{array}$ & $P$ \\
\hline \multicolumn{5}{|l|}{ Female } \\
\hline G1 (10-10.9) & $10.39 \pm 0.33$ & $10.93 \pm 1.22$ & -0.54 & 0.035 \\
\hline G2 (11-11.9) & $11.37 \pm 0.33$ & $12.11 \pm 1.34$ & -0.74 & 0.000 \\
\hline G3 (12-12.9) & $12.42 \pm 0.32$ & $13.10 \pm 1.50$ & -0.69 & 0.001 \\
\hline G4 (13-13.9) & $13.36 \pm 0.31$ & $14.81 \pm 1.45$ & -1.45 & 0.000 \\
\hline G5 (14-14.9) & $14.26 \pm 0.31$ & $16.05 \pm 0.94$ & -1.79 & 0.000 \\
\hline G6 (15-15.9) & $15.41 \pm 0.32$ & $16.85 \pm 0.95$ & -1.43 & 0.000 \\
\hline G7 (16-16.9) & $16.37 \pm 0.31$ & $17.23 \pm 1.19$ & -0.86 & 0.001 \\
\hline G8 (17-17.9) & $17.30 \pm 0.32$ & $17.71 \pm 0.81$ & -0.41 & 0.017 \\
\hline
\end{tabular}

diseases affecting the growth and development of the teeth and tooth agenesis excluding third molars were excluded because these could affect growth and development. ${ }^{[9-14]}$

Because GP method was based on a sample white children from a high socioeconomic level, who were born between 1917 and 1942, in the USA, ${ }^{[15]}$ the objective of our study was to attempt to determine whether the standards of the GP atlas are adequate for Southern Turkish children. There have been several factors that might affect the skeletal development between different populations even within the same country. Many investigators reported different results; Hackman and Black ${ }^{[5]}$ recommend that any analysis takes into account the potential for over- and under-aging shown in their study on Scottish Population. On the other hand, De Donno et al. ${ }^{[16]}$ reported that the GP atlas is usable on the Italian population since there were no significant differences in SA determination with this method as compared to the CA; Cantekin et al. ${ }^{[6]}$ evaluated the applicability of the GP method in Eastern Turkish children, and they reported that the mean differences between SA and CA are low enough to be of no practical significance. Koc et al. ${ }^{[7]}$ concluded that Turkish boys may have a different tempo of skeletal maturation during pubertal development from that of American children which GP standards were derived, and GP Atlas is not completely applicable to Turkish boys. Our study showed that GP standards are useful for Southern Turkish boys after 15 years old. GP standards overestimated approximately 1-year between 10 and 15-year-old boys. Interestingly, GP standards were underestimate for the Southern Turkish girls in all age groups. Especially between 13 and 16-year-old girls GP standards are not useful because the overestimation were approximately 1.5 years. This wide range between other studies and ours might be due to the ethnic differences, climate, nutrition, socioeconomic level, urbanization age distribution of the study samples, sample size, and statistical methods that were used. ${ }^{[6,7,17]}$ In addition, Southern Turkey is a quite different region compared to the other parts of the country. It has its unique hot-summer Mediterranean climate with hot and dry summers and mild and rainy winters. Therefore, it is expected that there should be some differences of skeletal maturation compared to other population.

\section{CONCLUSIONS}

Statistically significant differences were found in the CA and estimated SA assessed by GP method for the Southern Turkish sample.

Skeletal age was significantly underestimated in the 10-15 year ages in males and overestimated for 10-18 ages for females.

It is appropriate to use GP method in Southern Turkish children; however, a revision is needed for better results and to minimize the mistakes.

\section{REFERENCES}

1. Büken B, Safak AA, Yazici B, Büken E, Mayda AS. Is the assessment of bone age by the Greulich-Pyle method reliable at forensic age estimation for Turkish children? Forensic Sci Int 2007;173:146-53.

2. Patil ST, Parchand MP, Meshram MM, Kamdi NY. Applicability of Greulich and Pyle skeletal age standards to Indian children. Forensic Sci Int 2012;216:200.e1-4

3. Mansourvar M, Ismail MA, Raj RG, Kareem SA, Aik S, Gunalan R, et al. The applicability of Greulich and Pyle atlas to assess skeletal age for four ethnic groups. J Forensic Leg Med 2014;22:26-9.

4. Santoro V, Roca R, De Donno A, Fiandaca C, Pinto G, Tafuri S, et al. Applicability of Greulich and Pyle and Demirijan aging methods to a sample of Italian population. Forensic Sci Int 2012;221:153.e1-5.

5. Hackman L, Black S. The reliability of the Greulich and Pyle atlas when applied to a modern Scottish population. J Forensic Sci 2013;58:114-9.

6. Cantekin K, Celikoglu M, Miloglu O, Dane A, Erdem A. Bone age 
assessment: The applicability of the Greulich-Pyle method in eastern Turkish children. J Forensic Sci 2012;57:679-82.

7. Koc A, Karaoglanoglu M, Erdogan M, Kosecik M, Cesur Y. Assessment of bone ages: Is the Greulich-Pyle method sufficient for Turkish boys? Pediatr Int 2001;43:662-5.

8. Banerjee KK, Agarwal BB. Estimation of age from epiphyseal union at the wrist and ankle joints in the capital city of India. Forensic Sci Int 1998;98:31-9.

9. Gungor AY, Arica V, Gungor O, Tutanc M. Cephalometric evaluation of children with familial Mediterranean fever. Angle Orthod 2012;82:552-5.

10. Gungor AY, Turkkahraman H. Effects of severity and location of nonsyndromic hypodontia on craniofacial morphology. Angle Orthod 2013;83:584-90.

11. Yildirim D, Türkkahraman H, Yilmaz HH, Güngör AY, Ugan Y. Dentofacial characteristics of patients with rheumatoid arthritis. Clin Oral Investig 2013;17:1677-83.

12. Uysal T, Yagci A, Ramoglu SI. Dental maturation in patients with unilateral posterior crossbite. World J Orthod 2009;10:383-8.

13. Celikoglu M, Erdem A, Dane A, Demirci T. Dental age assessment in orthodontic patients with and without skeletal malocclusions. Orthod Craniofac Res 2011;14:58-62.

14. Celikoglu M, Kilkis D, Bayram M, Nur M. Farklı iskeletsel malokluzyonlarda Greulich ve Pyle atlasına göre kemik yasının değerlendirilmesi. Türk Ortodonti Derg 2012;25:21-30.

15. Loder RT, Estle DT, Morrison K, Eggleston D, Fish DN, Greenfield ML, et al. Applicability of the Greulich and Pyle skeletal age standards to black and white children of today. Am J Dis Child 1993;147:1329-33.

16. De Donno A, Santoro V, Lubelli S, Marrone M, Lozito P, Introna F. Age assessment using the Greulich and Pyle method on a heterogeneous sample of 300 Italian healthy and pathologic subjects. Forensic Sci Int 2013;229:157.e1-6.

17. Esenlik E, Atak A, Altun C. Evaluation of dental maturation in children according to sagittal jaw relationship. Eur J Dent 2014;8:38-43.

\begin{tabular}{|l|l|}
\hline \multicolumn{2}{|c|}{ Access this article online } \\
\hline Quick Response Code: & Website: \\
\hline & www.eurjdent.com \\
\hline
\end{tabular}

